\title{
Synthesis and Properties of New Small Band Gap Conjugated Polymers: Methine Bridged Poly(3,4-ethylenedioxypyrrole)
}

\author{
By Jung-Hsun TSAI, ${ }^{1}$ Wei-Ren TU, ${ }^{2}$ Cheng-Liang LIU, ${ }^{1}$ \\ Wen-Chung $W U^{2}$ and Wen-Chang CHEN $N^{1,2, *}$
}

\begin{abstract}
Synthesis and electronic properties of new small band gap conjugated polymers, methine-bridged poly(3,4-ethylenedioxypyrrole) (PEDOP) are reported. Density functional theory (B3LYP with 6-31G basis) are used to obtain the optimized ground-state geometries and electronic structures of PEDOP and poly[(3,4-ethylenedioxypyrrole-2,5-diyl) methine] (PEDOP-M). Theoretical bond length alternation of PEDOP is reduced by incorporating the methine bridge and leads to the band gap reduction from 2.44 to $0.68 \mathrm{eV}$. The small band gap characteristic of PEDOP-M is further verified by preparing two conjugated polymers, poly[(2,5- $n$-benzyl-3,4-ethylenedioxypyrrolediyl)-benzylidene-(2,5- $n$-benzyl-3,4-ethylenedioxypyrrole-quinodimethanediyl)] (PbEDOP-b) and poly[(2,5- $n$-benzyl-3,4-ethylenedioxypyrrolediyl)-( $p$-nitrobenzylidene)-(2,5- $n$ benzyl-3,4-ethylenedioxypyrrole-quinodimethanediyl)] (PbEDOP-nb). The optical band gap of PbEDOP-b and PbEDOPnb are 1.77 and $1.45 \mathrm{eV}$, respectively, while the electrochemical band gap of the former is $1.59 \mathrm{eV}$. Although the bulky side groups of these two polymers result in a larger band gap than that of PEDOT-M, it indicates the small band gaps of such polymers. The nitrobenzene group could extend the $\pi$-conjugation and lead to the smaller band gap of PbEDOP-nb than that of PbEDOP-b. The present study suggests that methine-bridged poly(3,4-ethylenedioxypyrrole) is a class of small band gap polymers.

KEY WORDS: Methine Bridged Polymers / Small Band Gap Polymers / Poly(3,4-ethylenedioxypyrrole) / Density Functional Theory /
\end{abstract}

Small band gap $\left(E_{g}\right)$ conjugated polymers have been extensively studied ${ }^{1-4}$ due to their potential applications in organic optoelectronic devices, ${ }^{1-12}$ such as photovoltaic cells, ${ }^{5,6}$ thin film transistors, ${ }^{7}$ light emitting diodes, ${ }^{8-10}$ electrochromic devices, ${ }^{11}$ and supercapacitors. ${ }^{12}$ The band gap of conjugated polymers can be manipulated through the molecular structures, such as bond length alternation (BLA), planarity, aromaticity, or donor/acceptor characteristics. ${ }^{1-3}$ Representative small band gap polymers include poly(isothianaphthene) (PITN), ${ }^{13,14}$ poly(thiophene methine) (PTMs), ${ }^{15-18}$ polysquaraines, ${ }^{3}$ poly(thiopyrazine), ${ }^{19,20}$ poly(cyclopentadithiophene), ${ }^{21}$ poly(thieno$[3,4$, b]thiophene $),{ }^{22}$ and ladder polymers. ${ }^{1-3}$

Conjugated polymers with alternating aromatic and quinoid isomers were shown to have intrinsic small band gaps, including poly(thiophene methine) (PTM), ${ }^{15-18}$ poly(isothianaphthene methine), ${ }^{23,24}$ poly(pyrrole methine),${ }^{25}$ and poly[(3,4-ethylenedioxythiophene-2,5-diyl) methine $].{ }^{26-28}$ In particular, the methine bridged conjugated polymers with the thiophene backbone exhibited relatively smaller band gap less than $1.0 \mathrm{eV}$. Recently, poly(3,4-dioxypyrrole) (PXDOP) has been widely studied since it exhibits unique properties of high conductivity, multicolor electrochromism, and rapid redox switching. ${ }^{29-32}$ Although the oxidation potentials of PXDOPs are very low ( $<0.05 \mathrm{~V}$ versus SCE), they exhibit middle to high band gaps of $2.0-3.4 \mathrm{eV} .{ }^{30}$ Besides, methine bridged poly $(3,4-$ dioxypyrrole) have not been synthesized and characterized yet.
Therefore, it would be worthwhile to explore the synthesis and properties of small band gap poly(3,4-ethylenedioxypyrrole) (PEDOP, 1 in Scheme 1) derivatives through the methinebridged approach, such as PEDOP (PEDOP-M, 2 in Scheme 1).

In this study, we report the synthesis and electronic properties of the methine bridged PEDOP. It is the first report on synthesis of such polymer to the best of our knowledge. Theoretical calculations based on density functional theory (DFT) were performed to obtain the ground-state geometries and electronic structures of PEDOP and PEDOP-M. Two methine-bridged PbEDOP derivatives, PbEDOP-b and PbEDOP-nb (3a and 3b, in Scheme 1), were synthesized via the acid-catalyzed polymerization of $n$-benzyl-3,4-ethylenedioxypyrrole (bEDOP) with benzaldehyde and 4-nitrobenzaldehyde, respectively. The bulky side groups at the bridge carbon of polymers $\mathbf{3}$ were introduced to provide enhanced solubility as compared with PEDOP-M. For the synthesis of small band gap conjugated polymers from acid-catalyzed polymerization, the mechanism of forming aromatic and quionid structure in the polymer structure was due to the dehydrogenation reaction from the methylene bridged polymers, poly(thiophene methine) ${ }^{15}$ or poly(3,4-ethylenedioxythiophene methine) (PEDOT-M) ${ }^{28}$ The theoretical electronic properties of the non-substituted PEDOT-M were shown to be consistent with the experimental results from the bulky side

\footnotetext{
${ }^{1}$ Department of Chemical Engineering, National Taiwan University, Taipei, Taiwan 106

2 Institute of Polymer Science and Engineering, National Taiwan University, Taipei, Taiwan 106

*To whom correspondence should be addressed (Tel: +886-2-23628398, Fax: +886-2-23623040, E-mail: chenwc@ntu.edu.tw).
} 


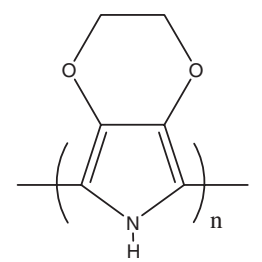

1, PEDOP

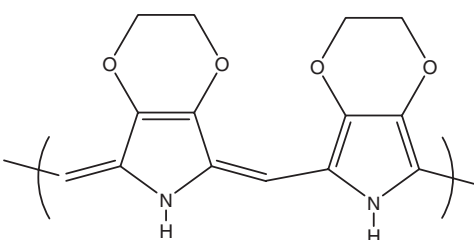

2, PEDOP-M

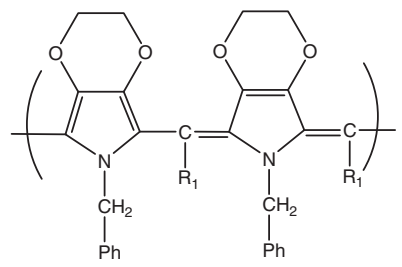

3a $\quad \mathbf{R}_{1}=\mathrm{Ph}$ (PbEDOP-b)

3b $\quad \mathrm{R}_{1}=\mathrm{PhNO}_{2}(\mathrm{PbEDOP}-\mathrm{nb})$

Scheme 1.

group-substituted analogs. Hence, the acid-catalyzed polymerization of $n$-benzyl-3,4-ethylenedioxypyrrole (bEDOP) with benzaldehyde and 4-nitrobenzaldehyde would lead to the proposed polymer structure with alternating aromatic and quionid structure. Also, the theoretical calculation on the electronic properties of PEDOP-M could be used to compare with the experimental results from PbEDOP-b and PbEDOPnb. The polymer structures, thermal, optical and electrochemical properties of polymers 3 were characterized. The experimental electronic properties of the prepared methine-bridged PbEDOP derivatives were compared with those from the theoretical results to justify the small band gap characteristics.

\section{Theoretical Methodology on the Electronic Structure}

All of the calculations were performed on Gaussain $03^{33}$ by using density functional theory (DFT): Becke's three-parameter hybrid functional ${ }^{34}$ combined with Lee, Yang, and Parr's correlation functional $^{35,36}$ (B3LYP) was used with 6-31G basis set. The geometries and electronic properties were calculated by assuming all the polymers to be isolated, infinite, one dimensional (linear) polymers. The starting unit cell geometries were taken from the central part of corresponding oligomers, and then fully optimized to the equilibrium geometries inside a given lattice length on the constraints of periodic boundary conditions by assuming that the unit cell is repeated identically an infinite number of times along the translation vector. Both the lattice parameter and molecular structures were varied to locate the lowest energy position in the unit cell.

\section{EXPERIMENTAL}

\section{Materials}

Benzyl-3,4-ethylenedioxypyrrole-2,5-dicarboxylate $(95 \%$, Aldrich), triethanolamine (99\%, Riedel-deHaën), benzaldehyde (>98\%, Acros), 4-nitrobenzaldehyde (99\%, Acros), sulfuric acid (Baker, 96\%), hydrochloric acid and solvents were purchased from Aldrich or Acros without further purification.

\section{Synthesis}

The synthetic routes of monomers and corresponding polymers are shown in Scheme 2. 6-benzyl-3,6-dihydro-2H[1,4]dioxino[2,3-c]pyrrole-5,7-dicarboxylic acid (1) and 6benzyl-3,6-dihydro-2H-[1,4]dioxino[2,3-c]pyrrole (bEDOP, 2), were synthesized according to the literature. ${ }^{32}$ The general procedure of synthesizing methine-bridged polymers of PbEDOP-b and PbEDOP-nb were through acid-catalyzed polymerization reported previously by one of us. ${ }^{15,16}$

Poly[(2,5- $n$-benzyl-3,4-ethylenedioxypyrrolediyl)benzylidene(2,5-n-benzyl-3,4-ethylenedioxypyrrole-quinodimethanediyl)] $(\boldsymbol{P b E D O P}-\boldsymbol{b})$. The polymerization mixture was $n$-benzyl3,4-ethylenedioxypyrrole $(300 \mathrm{mg}, 1.39 \mathrm{mmol})$, benzaldehyde (174.34 mg, $1.61 \mathrm{mmol}), 4 \mathrm{~mL}$ of $p$-dioxane, and $47 \mathrm{mg}$ $(0.46 \mathrm{mmol})$ of $98 \%$ sulfuric acid. The reaction temperature was kept at $65^{\circ} \mathrm{C}$ for $24 \mathrm{~h}$. A dark purple reaction solution was precipitated into $300 \mathrm{~mL}$ of stirring methanol, recovered, recrystallized from THF/hexane, and dried in a vacuum oven at $40{ }^{\circ} \mathrm{C}$ for $12 \mathrm{~h}$. The yield was $60 \% .{ }^{1} \mathrm{H}$ NMR (DMSO- $d_{6}$ ): $\delta=3.40-4.38\left(8 \mathrm{H}, 4\left(-\mathrm{CH}_{2}\right)\right), 4.52-5.30\left(4 \mathrm{H}, 2\left(-\mathrm{CH}_{2}\right)\right), 6.00$ $7.65(20 \mathrm{H}$, phenyl rings). Molecular weight: weight-average molecular weight $\left(M_{\mathrm{w}}\right)=4930$, polydispersity index $(\mathrm{PDI})=$ 1.62. Anal. Calcd. for $\left(\mathrm{C}_{40} \mathrm{H}_{33} \mathrm{~N}_{2} \mathrm{O}_{4}\right)_{\mathrm{n}}$ : C, 79.45; H, 5.33; N, 4.63. Found: C, 77.40; H, 5.71; N, 4.48. FT-IR (film on KBr, $\left.\mathrm{cm}^{-1}\right)$ : 3058, 3025, 2940, 2859, 1601, 1491, 1452.

Poly[(2,5-n-benzyl-3,4-ethylenedioxypyrrolediyl)( $p$-nitrobenzylidene)(2,5-n-benzyl-3,4-ethylenedioxypyrrolequinodimethanediyl)] (PbEDOP-nb). The polymerization mixture was $n$ benzyl-3,4-ethylenedioxypyrrole ( $400 \mathrm{mg}, 1.85 \mathrm{mmol}$ ), 4-nitrobenzaldehyde $(325.66 \mathrm{mg}, 2.15 \mathrm{mmol}), 5 \mathrm{~mL}$ of $p$-dioxane, and $63 \mathrm{mg}(0.62 \mathrm{mmol})$ of $98 \%$ sulfuric acid. The reaction temperature was kept at $60^{\circ} \mathrm{C}$ for $24 \mathrm{~h}$. A dark purple reaction solution was precipitated into $400 \mathrm{~mL}$ of stirring methanol, recovered, recrystallized from THF/hexane, and dried in a vacuum oven at $40{ }^{\circ} \mathrm{C}$ for $12 \mathrm{~h}$. The yield was $70 \% .{ }^{1} \mathrm{H}$ NMR (DMSO- $d_{6}$ ): $\delta=3.40-4.40\left(8 \mathrm{H}, 4\left(-\mathrm{CH}_{2}\right)\right), 4.40-5.31\left(4 \mathrm{H}, 2\left(-\mathrm{CH}_{2}\right)\right), 6.02-$ $8.45\left(18 \mathrm{H}\right.$, phenyl rings). Anal. Calcd. for $\left(\mathrm{C}_{40} \mathrm{H}_{30} \mathrm{~N}_{4} \mathrm{O}_{8}\right)_{\mathrm{n}}$ : C, 69.39; H, 4.88; N, 7.83. Found: C, 67.56; H, 4.90; N, 7.57. FTIR (film on $\mathrm{KBr}, \mathrm{cm}^{-1}$ ): 3062, 3030, 2973, 2927, 2869, 1585, $1573,1516,1452,1343$. Molecular weight: $M_{\mathrm{w}}=5160$, $\mathrm{PDI}=1.30$.

\section{Characterization}

${ }^{1} \mathrm{H}$ nuclear magnetic resonance (NMR) data was obtained by a Bruker AV $300 \mathrm{MHz}$ spectrometer. FT-IR spectrum of the prepared polymer on $\mathrm{KBr}$ pellet was obtained using a Jasco Model FT-IR 410 spectrophotometer at room temperature. The sample was scanned 32 times with resolution $4 \mathrm{~cm}^{-1}$. Gel permeation chromatographic analysis was performed on a Lab Alliance RI2000 instrument (two column, MIXED-C and D from Polymer Laboratories) connected with one refractive index detector from Schambeck SFD Gmbh. All GPC analyses were performed on polymer/THF solution at a flow rate of $1 \mathrm{~mL} / \mathrm{min}$ at $40^{\circ} \mathrm{C}$ and calibrated with polystyrene standards. 
monomers:<smiles>CCOC(=O)c1c2c(c(C(=O)O)n1Cc1ccccc1)OCCO2</smiles>

Scheme 2

Thermogravimetric analysis (TGA) and differential scanning calorimetry (DSC) measurements were performed under a nitrogen atmosphere at a heating rate of 20 and $10^{\circ} \mathrm{C} / \mathrm{min}$ using a TA instrument TGA-951 and DSC-910S, respectively. UV-visible absorption spectra were recorded on a Jasco model UV/VIS/NIR V-570 spectrometer. For the solution spectra, polymers were dissolved in THF $\left(\mathrm{ca} \cdot 10^{-6} \mathrm{M}\right)$ and then put in a quartz cell for measurement. For the thin film spectra, polymers were first dissolved in THF ( $1 \mathrm{wt} \%)$ and then spin-coated on glass substrate at $1000 \mathrm{rpm}$ for $30 \mathrm{~s}$. Then, the thin film samples were dried at $60^{\circ} \mathrm{C}$ under vacuum for measurement.

The electrochemical properties of the polymer films were investigated on a Princeton Applied Research Model 273A Potentiostat/Galvanostat with a $0.1 \mathrm{M}$ acetonitrile $(99.5+\%$, Tedia) solution containing tetrabutylammonium tetrafluoroborate $\left(\mathrm{TBABF}_{4}\right)($ Fluka, $>99.9 \%)$ as the electrolyte. Platinum wire and rod-tip electrodes were used as counter and working electrodes respectively. Silver/silver ion (Ag in $0.1 \mathrm{M} \mathrm{AgNO}_{3}$ (Acros, 99.8\%) in the supporting electrolyte solutions) was used as a reference electrode. A $3 \mathrm{wt} \%$ solution of a polymer in THF or DMSO was used to prepare the polymer film on the $\mathrm{Pt}$ rod-tip electrode. Then, the cyclic voltammetry of films was performed on a three-electrode cell. The reference electrode was calibrated through by the cyclic voltammetry of ferrocene without any polymer added into the solution. The cyclic voltammograms were obtained at a voltage scan rate of 40 $\mathrm{mV} / \mathrm{s}$. The potential values obtained versus $\mathrm{Fc}^{+} / \mathrm{Fc}$ standard were converted to the saturated calomel electrode (SCE) scale by adding a constant voltage to them. The energy parameters EA and IP were estimated from the measured redox potentials on the basis of the prior work on conjugated polymers which has shown that: $\mathrm{IP}=\left(\mathrm{E}_{\mathrm{ox}}+4.4\right)$ and $\mathrm{EA}=\left(\mathrm{E}_{\mathrm{red}}+4.4\right)$, where the onset potentials are in volts (vs. SCE) and IP and EA are in electron volts. The $4.4 \mathrm{eV}$ constant in the relation among IP, $\mathrm{EA}$, and redox potentials is the SCE energy level versus vacuum. The electronic structure parameters, HOMO and LUMO, were estimated with the relation of $\mathrm{HOMO}=-\mathrm{IP}$ and LUMO $=-$ EA by assuming no configuration interactions.

\section{RESULT AND DISCUSSION}

Geometric and Electronic Structures of Studied Polymers

Theoretical analysis on the geometries and electronic structures of PEDOP and PEDOP-M was performed to investigate the effect of methine-bridged backbone on the electronic properties. Figure 1 shows the optimized unit cell 


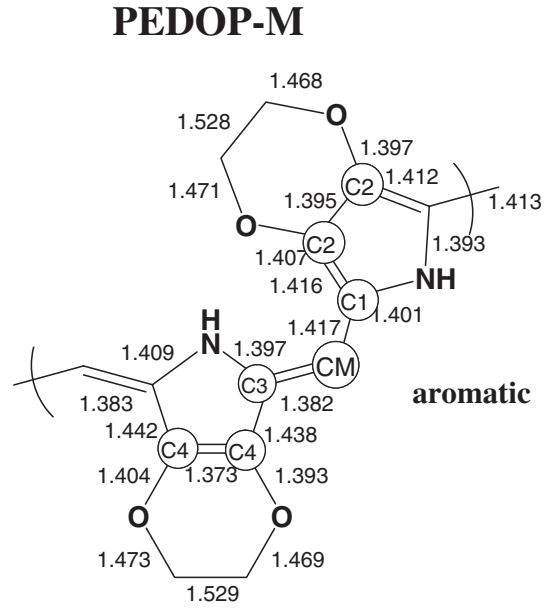

quinoid

\section{PEDOP}

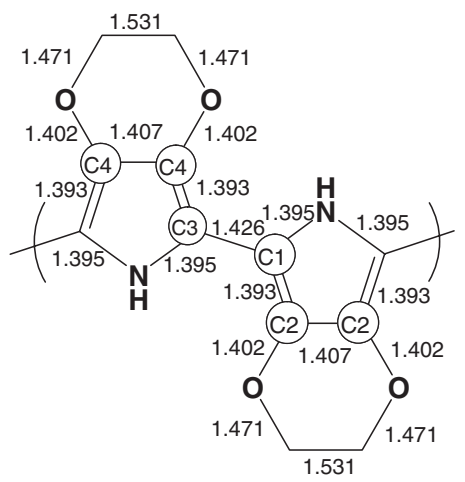

aromatic

Figure 1. The optimized unit cell geometries of PEDOP-M and PEDOP.

Table I. Geometric and electronic parameters of PEDOP-M and PEDOP

\begin{tabular}{|c|c|c|c|c|c|c|c|}
\hline & \multicolumn{4}{|c|}{ bond lengths $(\AA)^{a}$} & \multicolumn{3}{|c|}{ electronic parameters ${ }^{b}$} \\
\hline & $\mathrm{R}_{(\mathrm{C1}-\mathrm{CM})} / \mathrm{R}_{(\mathrm{C} 3-\mathrm{CM})}$ & $\mathrm{R}_{(\mathrm{C} 1-\mathrm{C} 2)} / \mathrm{R}_{(\mathrm{C} 2-\mathrm{C} 2)}$ & $\mathrm{R}_{(\mathrm{C} 3-\mathrm{C} 4)} / \mathrm{R}_{(\mathrm{C} 4-\mathrm{C} 4)}$ & BLA & $\begin{array}{c}\text { IP } \\
(\mathrm{eV})\end{array}$ & $\begin{array}{c}\text { EA } \\
(\mathrm{eV})\end{array}$ & $\begin{array}{c}E_{g} \\
(e V)\end{array}$ \\
\hline PEDOP-M & $1.417 / 1.382$ & $1.416 / 1.395$ & $1.438 / 1.373$ & 0.028 & 2.54 & 1.86 & 0.68 \\
\hline PEDOP & - & $1.393 / 1.407$ & $1.393 / 1.407$ & 0.033 & 2.98 & 0.54 & 2.44 \\
\hline
\end{tabular}

${ }^{\mathrm{a}}$ The numbering of carbon atoms is shown in Figure 1. ${ }^{\mathrm{b}} \mathrm{IP} / \mathrm{EA}$ estimated as below: IP $=-\mathrm{HOMO}, \mathrm{EA}=-\mathrm{LUMO}$.

geometry of PEDOP-M and PEDOP, and the corresponding geometric and electronic parameters are listed in Table I. In general, a smaller bond length alternation (BLA, of adjacent $\mathrm{C}-\mathrm{C}$ and $\mathrm{C}=\mathrm{C}$ bonds on the backbone) provides a better $\pi$-delocalization through the polymer backbone and usually leads to a smaller band gap. ${ }^{37}$ The BLA estimated from the optimized geometry is defined as the difference of averaged single-bond length and averaged double-bond length on the backbone. For PEDOP-M, the averaged single-bond length and averaged double-bond length on the backbone are 1.421 and $1.393 \AA$, respectively, and thus the corresponding BLA is $0.028 \AA$. On the other hand, the averaged single-bond length, averaged double-bond length, and BLA of PEDOP are 1.426, 1.393 , and $0.033 \AA$, respectively. It suggests that the incorporation of the methine bridge to PEDOP results in the smaller BLA of PEDOP-M.

The estimated band gap for PEDOP-M is $0.68 \mathrm{eV}$, which is much smaller than that of PEDOP with $2.44 \mathrm{eV}$. The band gap reduction is probably attributed to the smaller bond length alternation of PEDOP-M than the PEDOP, as described above. If the bond length alternation is small, the HOCO (highest occupied crystal orbital) antibonding interaction would be strengthened but the bonding interaction would be weakened. However, the case of LUCO (lowest unoccupied crystal orbital) shows a reverse trend as that of the HOCO: the bonding interaction would be strengthened whereas antibonding interaction would be weakened. ${ }^{38}$ In this case, the HOCO level of the PEDOP-M is destabilized by $0.44 \mathrm{eV}$, and the LUCO level of the PEDOP-M is stabilized by $1.32 \mathrm{eV}$ relative to those of PEDOP. The above variation on the band structure results in much smaller band gap of PEDOP-M as compared to PEDOP. The smaller IP of PEDOP-M also indicates the lower oxidation potential of PEDOP-M as compared to PEDOP. The theoretical results suggest that the methine-bridged PEDOP-M has a much smaller band gap than parent PEDOP.

Another interesting issue is to compare the difference on the theoretical electronic structures of methine bridged PEDOP and polypyrrole. The theoretical electronic properties of the methine bridged pyrrole using the same methodology are described as below: IP $(3.20 \mathrm{eV})$, EA $(2.47 \mathrm{eV})$, and $\mathrm{Eg}$ $(0.73 \mathrm{eV})$. In comparison, the electronic properties of PEDOP$\mathbf{M}$ are IP $(2.54 \mathrm{eV}), \mathrm{EA}(1.86 \mathrm{eV})$, and $\mathrm{Eg}(0.68 \mathrm{eV})$. The incorporation of the dioxy group leads to the lower IP of methine bridged PEDOP than that of the methine bridged pyrrole.

\section{Polymer Synthesis and Structure}

The solubility of PEDOP-M would be poor for characterization and thus PbEDOP-b (3a) and PbEDOP-nb (3b) with a bulky side group were synthesized for exploring the electronic properties. Similar to the reported PTM, ${ }^{15,16}$ the polymer products obtained from the acid-catalyzed polymerization of the bEDOP with aldehydes were highly colored, indicating its conjugated backbone. The obtained polymers were soluble in 

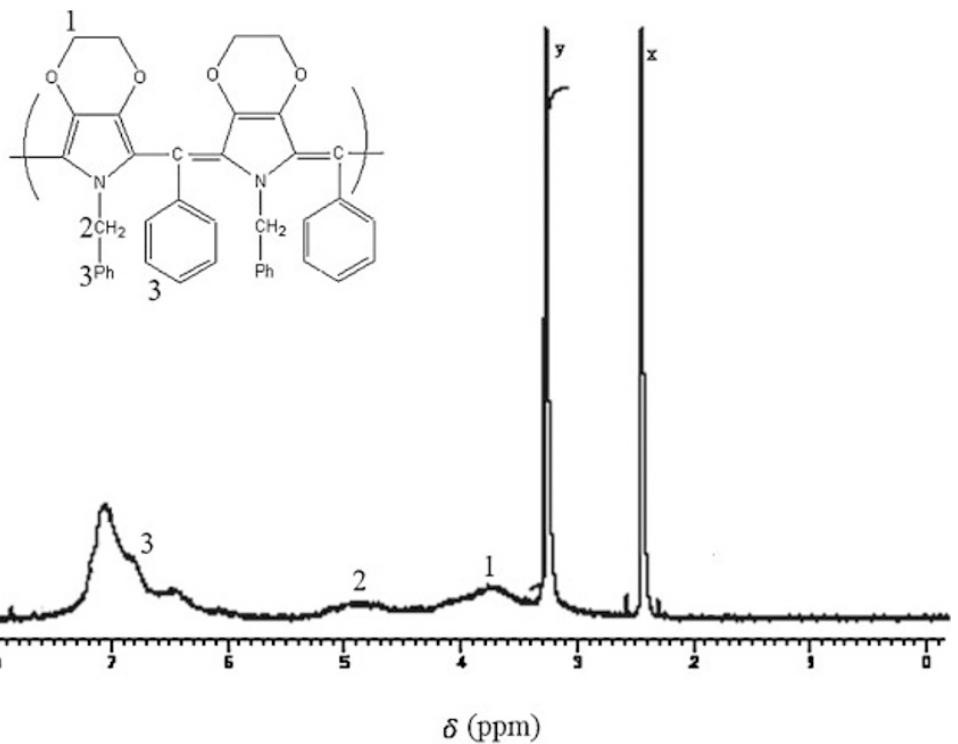

Figure 2. The ${ }^{1} \mathrm{H}$ NMR spectra of the PbEDOP-b in dimethyl sulfoxide- $d_{6}$ (DMSO). The peaks labeled as $\mathrm{x}$ and $\mathrm{y}$ are assigned to the DMSO solvent and water, respectively.

organic solvents, such as $\mathrm{CHCl}_{3}$, DMF, DMSO, acetone, and THF, at room temperature. The average molecular weights $\left(M_{\mathrm{w}}\right.$, PDI) measured by GPC with respect to PS standard of PbEDOP-b and PbEDOP-nb are (4930, 1.62) and (5160, $1.30)$, respectively.

Figure 2 illustrates the ${ }^{1} \mathrm{H}$ NMR spectrum of PbEDOP-b in DMSO- $d_{6}$. The peaks labeled as $\mathrm{x}$ and $\mathrm{y}$ are assigned to the DMSO solvent $(\delta=2.5 \mathrm{ppm})$ and water in DMSO- $d_{6}(\delta=$ $3.3 \mathrm{ppm})$, respectively. The broad proton resonance around $3.73 \mathrm{ppm}$ is attributed to be the ethylenedioxy moiety of PbEDOP-b. Note that the same proton resonance of PbEDOP$\mathbf{n b}$ is around $3.93 \mathrm{ppm}$ as shown in the supporting information (Figure S1). The absence of proton signal in the region of 5.56.0 ppm suggests that PbEDOP-b is fully dehydrogenated. PbEDOP-nb also shows the fully dehydrogenated NMR spectrum. The electron-donating ethylenedioxy moiety could enhance dehydrogenation reactivity and facilitate the formation of the quinoid moieties, which leads to the desired conjugated polymers. Figure 3 shows the FT-IR absorption spectra of the PbEDOP-b and PbEDOP-nb in the range of 500-4000 $\mathrm{cm}^{-1}$. The absorption band at $2850-3000 \mathrm{~cm}^{-1}$ is contributed from the $\mathrm{C}-\mathrm{H}$ stretching vibration of methylene group on the ethylenedioxy-ring or benzyl group. The absorption band at $3100 \mathrm{~cm}^{-1}$ represents the $\mathrm{C}-\mathrm{H}$ stretching vibration $\left(-\mathrm{sp}^{2}\right)$ of pyrrole or phenyl rings. The absorption peaks within 1600$1700 \mathrm{~cm}^{-1}$ suggest that the formation of the quinoid geometry in the main chain. The $\mathrm{C}=\mathrm{C}$ double bond in the main chain rings shows its symmetric and asymmetric absorption at 1450 and $1500 \mathrm{~cm}^{-1}$, respectively. The two strong absorption bands at 1343 and $1516 \mathrm{~cm}^{-1}$ in the spectrum of PbEDOP-nb are assigned to the symmetric and asymmetric of stretching vibration of $\mathrm{N}-\mathrm{O}$ and $\mathrm{N}=\mathrm{O}$ bonding in the $p$-nitrobenzylidene moiety, respectively. The rather weak bands at $2869 \mathrm{~cm}^{-1}$ in PbEDOP-nb are probably attributed to the overtones of the $\mathrm{NO}_{2}$ symmetric stretching vibration bands. The absorption

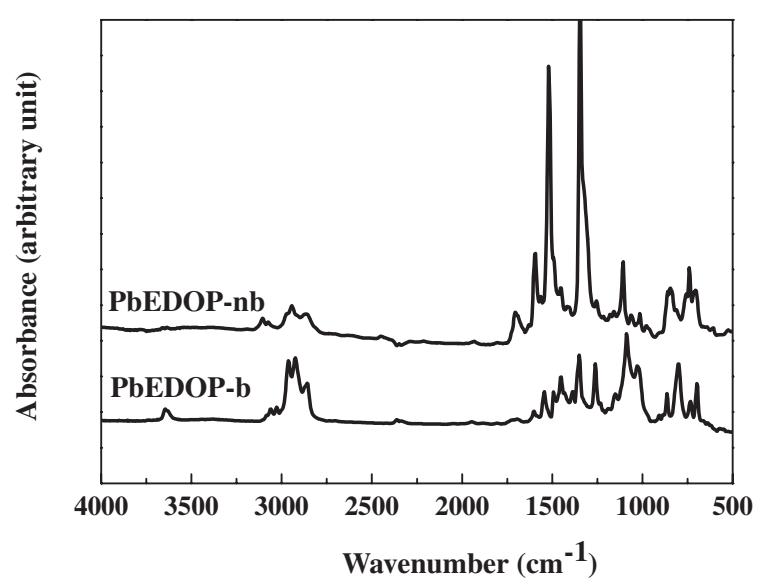

Figure 3. FT-IR absorption spectra of the PbEDOP-nb and PbEDOP-b on $\mathrm{KBr}$ in the range of $500-4000 \mathrm{~cm}^{-1}$.

band at $1250 \mathrm{~cm}^{-1}$ of PbEDOP-b and PbEDOP-nb are assigned to the C-O-C stretching vibrations from the ethylenedioxy moiety. The NMR and FT-IR results agree well with the proposed structures of polymer 3 shown in Scheme 1.

The elemental analysis results of these two polymers show a fair agreement with theoretical compositions. The analytic data of these two polymers showed about $2 \%$ difference with the expected carbon content, which are probably due to the end group effect of low molecular weight polymers.

\section{Thermal Properties}

Figure 4 shows the TGA curves of PbEDOP-b and PbEDOP-nb under nitrogen atmosphere. The thermal decomposition temperatures of PbEDOP-b and PbEDOP-nb are 300 and $281^{\circ} \mathrm{C}$, respectively. The slight weight loss at the early stage of heating is probably resulting from the easy disruption 


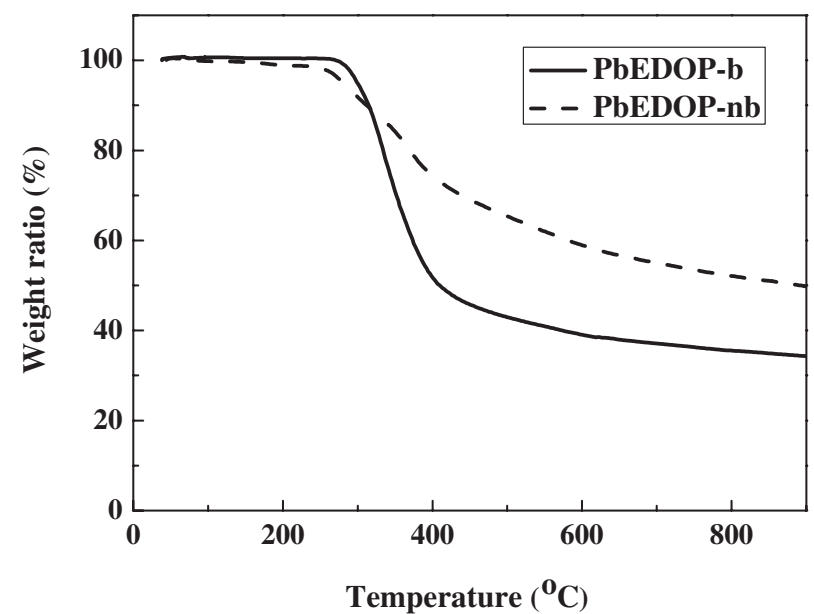

Figure 4. TGA curves of the PbEDOP-nb and PbEDOP-b obtained in flowing $\mathrm{N}_{2}$ at a heating rate of $20^{\circ} \mathrm{C} / \mathrm{min}$.

of the ethylenedioxy moieties. No observable glass transition temperature $\left(T_{\mathrm{g}}\right)$ is observed in the DSC curves, indicating rigid backbones of methine-bridged PbEDOPs.

\section{Optical and Electrochemical Properties}

Figure 5 shows the UV-vis-NIR absorption spectra of the PEDOP-nb and PEDOP-b solution in THF and thin films, respectively. In Figure 5(a), the absorption maxima $\left(\lambda_{\max }\right)$ of PbEDOP-nb in THF are observed at 240, 266, 388, and $589 \mathrm{~nm}$, respectively. The absorption bands with the $\lambda_{\max }$ at 240 and $266 \mathrm{~nm}$ is assigned to the $\pi-\pi^{*}$ transition of the ethylenedioxypyrrole and $p$-nitrobenzylidene moieties, respectively. The other two absorption peaks at 388 and $589 \mathrm{~nm}$ in PbEDOP-nb are attributed to highly conjugated moieties with different degree of conjugation. The absorption spectrum of PbEDOP-b in THF shows two major absorption bands at 237 and $516 \mathrm{~nm}$, which are attributed to the EDOP and $\pi$-conjugated backbone, respectively. The larger $\lambda_{\max }$ of PbEDOP-nb than that of PbEDOP-b is attributed to the extended $\pi$-electron delocalization from the nitrobenzene group on the side chain. Another possibility is donor-aceptor intramolecular charge transfer between EDOP and nitrobenzene moieties. The absorption spectrum of PbEDOP-nb film shows three major absorption bands with $\lambda_{\max }$ at 269, 395, and $623 \mathrm{~nm}$, respectively. Similarly, for the PbEDOP-b film, two major absorption bands at 204 and $522 \mathrm{~nm}$ are observed and that at $522 \mathrm{~nm}$ is attributed to highly $\pi$-conjugated backbone. The film absorption spectra of both polymers are red-shifted from that of solution due to the enhanced interchain interaction. The estimated band gaps of the PbEDOP-nb and PbEDOP-b from the absorption edges are about 1.45 and $1.77 \mathrm{eV}$, respectively. They are significantly smaller than those (2.0$3.4 \mathrm{eV}$ ) of PXDOPs. ${ }^{30}$ It suggests the successful reduction of band gap through the incorporation of methine bridge.

The electronic structure and properties of the PbEDOP-b were further explored by cyclic voltammetry. Figure 6 shows the cyclic voltammogram (CV) of the PbEDOP-b in the potential range from -2 to $1 \mathrm{~V}$ ( $v s$. SCE) at the sweep rate of
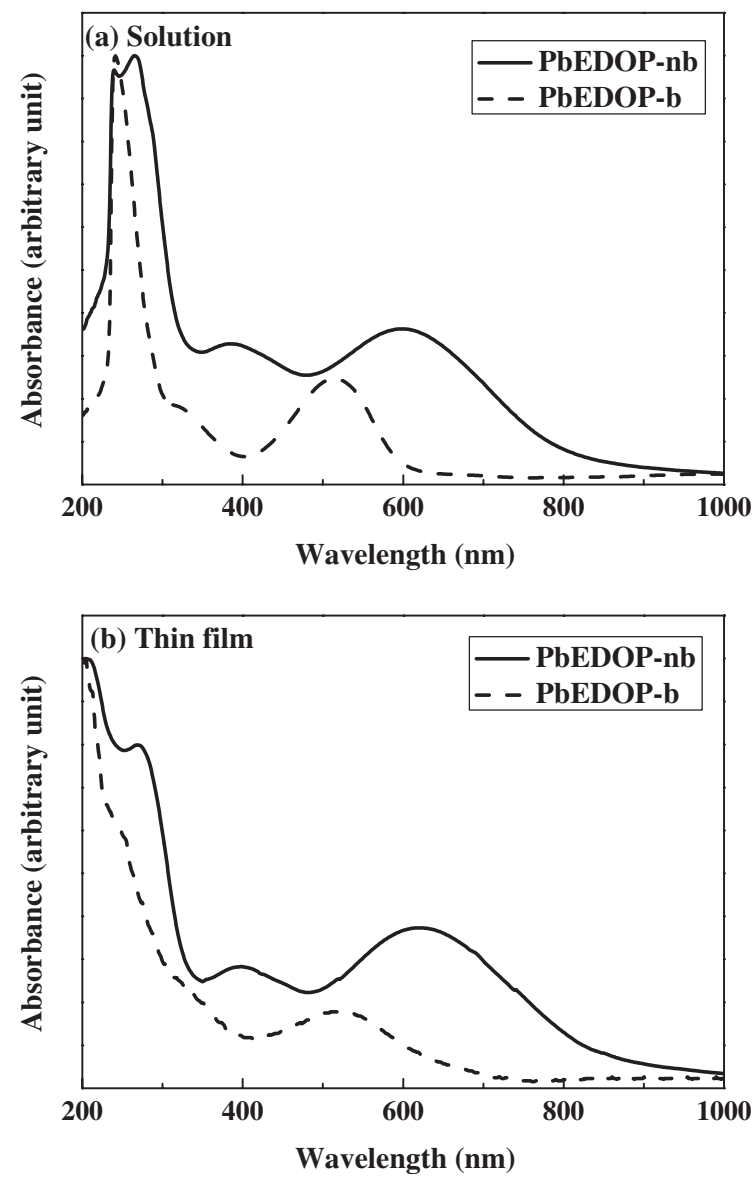

Figure 5. The UV-vis-NIR absorption spectra of PbEDOP-nb and PbEDOPb in THF (a), and in thin films (b).

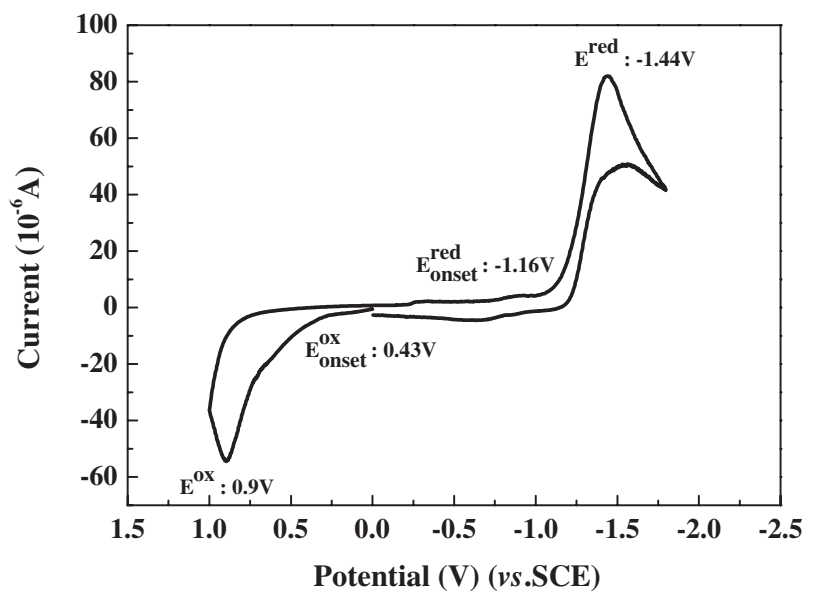

Figure 6. Cyclic voltammogram of the PbEDOP-b in $0.1 \mathrm{M} \mathrm{TBABF} 4 /$ acetonitrile solution at a sweep rate of $40 \mathrm{mV} / \mathrm{s}$.

$40 \mathrm{mV} / \mathrm{s}$. The peak potentials $\left(\mathrm{E}_{\mathrm{p}}\right)$ for the electrochemical oxidation and reduction of the PbEDOP-b are shown at +0.90 and $-1.44 \mathrm{~V}$, respectively. The onset potentials $\left(\mathrm{E}_{\mathrm{on}}\right)$ for the oxidation and reduction of PbEDOP-b are shown at +0.43 and $-1.16 \mathrm{~V}$, respectively, which correspond to an ionization potential (IP) of $4.89 \mathrm{eV}$ and electron affinity of $3.30 \mathrm{eV}$, 
respectively. Thus, the electrochemical band gap $\left(\mathrm{E}_{\mathrm{g}}^{\mathrm{el}}=\right.$ IP - EA) of the PbEDOP-b is estimated to be $1.59 \mathrm{eV}$, which is lower than the optical band gap of $0.18 \mathrm{eV}$. PbEDOP-nb is very soluble in most solvents for $\mathrm{CV}$ measurement and its electrochemical properties could not be obtained, including acetonitrile, propylene carbonate, dichloromethane, and benzonitrile. Nevertheless, the electrochemical properties confirm that the band gap of the methine-bridged PbEDOP-b is smaller than that of PEDOP around $2.0 \mathrm{eV}$, which is in consistent with the theoretical results.

\section{CONCLUSIONS}

New small band gap conjugated polymers of methine bridged conjugated poly(3,4-ethylenedioxypyrrole) were studied. The theoretical analysis suggested that the incorporating methine-bridge into poly(3,4-ethylenedioxypyrrole) decreased the bond length alternation and led to the reduction of band gap. The theoretical band gap of PEDOP-M was $0.68 \mathrm{eV}$, significantly smaller than that of PEDOP with $2.44 \mathrm{eV}$. Two soluble methine-bridged poly(3,4-ethylenedioxypyrrole), PbEDOP-b and PbEDOP-nb, were successfully synthesized by acid-catalyzed polymerization. The experimental band gaps of PbEDOP-b and PbEDOP-nb also suggested the small band gap characteristics. The small band gap characteristics of new methine-bridged poly(3,4-ethylenedioxypyrrole) may have potential applications in electronic and optoelectronic applications.

Acknowledgment. The financial supports from National Science Council, the Ministry of Education, and the Ministry of Economic Affairs of Taiwan are highly appreciated.

Electronic Supporting Information Available: Figures S1. These materials are available via the Internet at http:// www.spsj.or.jp/c5/pj/pj.htm

Received: October 18, 2008 Accepted: January 13, 2009

Published: March 4, 2009

\section{REFERENCES}

1. J. Roncali, Chem. Rev., 97, 173 (1997).

2. H. A. M. van Mullekom, J. A. J. M. Vekemans, E. E. Havinga, and E. W. Meijer, Mater. Sci. Eng., R, 32, 1 (2001).

3. N. Matsumi and Y. Chujo, Polym. J., 40, 77 (2008).

4. E. Bundgaard and F. C. Krebs, Sol. Energy Mater. Sol. Cells, 91, 954 (2007).

5. F. Zhang, W. Mammo, L. M. Andersson, S. Admassie, M. R. Andersson, and O. Inganäs, Adv. Mater., 18, 2169 (2006).

6. C. Soci, I.-W. Hwang, D. Moses, Z. Zhu, D. Waller, R. Gaudiana, C. J. Brabec, and A. J. Heeger, Adv. Funct. Mater., 17, 632 (2007).

7. W. Y. Lee, C. W. Chen, C. C. Chueh, C. C. Yang, and W. C. Chen, Polym. J., 40, 249 (2008).

8. W. C. Wu, W. Y. Lee, and W. C. Chen, Macromol. Chem. Phys., 207, 1131 (2006).

9. A. P. Kulkarni, Y. Zhu, and S. A. Jenekhe, Macromolecules, 38, 1553
(2005).

10. Y. Lee, S. Sadki, B. Tsuie, and J. R. Reynolds, Chem. Mater., 13, 2234 (2001).

11. F. Fusalba, H. A. Ho, L. Breau, and D. Belanger, Chem. Mater., 12, 2581 (2000).

12. R. Kiebooms, I. Hoogmartens, P. Adriaensens, D. Vanderzande, and J. Gelan, Macromolecules, 28, 4961 (1995).

13. H. Meng and F. Wudl, Macromolecules, 34, 1810 (2001).

14. S. A. Jenekhe, Nature, 322, 345 (1986).

15. W. C. Chen and S. A. Jenekhe, Macromolecules, 28, 465 (1995).

16. M. Hanack, U. Schmid, S. Echinger, F. Teichert, and J. Hieber, Synthesis, 634 (1993).

17. Q. Zhang, M. Yang, P. Wu, and H. Ye, X. Liu, Synth. Met., 156, 135 (2006).

18. M. Karikomi, C. Kitamura, S. Tanaka, and Y. Yamashita, J. Am. Chem. Soc., 117, 6791 (1995).

19. J. Kastnar, H. Kuzamany, D. Vegh, M. Landl, L. Cuff, and M. Kertesz, Macromolecules, 28, 2922 (1995).

20. T. L. Lambert and J. P. Ferraris, J. Chem. Soc., Chem. Commun., 11, 752 (1991)

21. C. Quattrocchi, R. Lazzaroni, J. L. Bredas, R. Zamboni, and C. Taliani, Macromolecules, 26, 1260 (1993).

22. C. J. Neef, I. D. Brotherston, and J. P. Ferraris, Chem. Mater., 11, 1957 (1999).

23. R. Kiebooms and F. Wudl, Synth. Met., 101, 40 (1999).

24. R. H. L. Kiebooms, H. Goto, and K. Akagi, Macromolecules, 34, 7989 (2001).

25. H. Goto and K. Akagi, J. Polym. Sci., Part A: Polym. Chem., 43, 616 (2005).

26. T. Benincori, S. Rizzo, F. Sannicolò, G. Schiavon, S. Zecchin, and G. Zotti, Macromolecules, 36, 5114 (2003).

27. W. C. Chen, C. L. Liu, C. T. Yen, F. C. Tsai, C. J. Tonzola, N. Olson, and S. A. Jenekhe, Macromolecules, 37, 5959 (2004).

28. M. B. Zaman and D. F. Perepichka, Chem. Commun., 4187 (2005).

29. P. Schottland, K. Zong, C. L. Gaupp, B. C. Thompson, C. A. Thomas, I. Giurgiu, R. Hickman, K. A. Abboud, and J. R. Reynolds, Macromolecules, 33, 7051 (2000).

30. G. Sonmez, P. Schottland, K. Zong, and J. R. Reynolds, J. Mater. Chem., 11, 289 (2001).

31. R. M. Walczak and J. R. Reynolds, Adv. Mater., 18, 1121 (2006)

32. K. Zong and J. R. Reynolds, J. Org. Chem., 66, 6873 (2001).

33. Gaussian 03, Revision B.4, M. J. Frisch, G. W. Trucks, H. B. Schlegel, G. E. Scuseria, M. A. Robb, J. R. Cheeseman, J. A. Montgomery, T. Vreven, Jr., K. N. Kudin, J. C. Burant, J. M. Millam, S. S. Iyengar, J. Tomasi, V. Barone, B. Mennucci, M. Cossi, G Scalmani, N. Rega, G. A. Petersson, H. Nakatsuji, M. Hada, M. Ehara, K. Toyota, R. Fukuda, J. Hasegawa, M. Ishida, T. Nakajima, Y. Honda, O. Kitao, H. Nakai, M. Klene, X. Li, J. E. Knox, H. P. Hratchian, J. B. Cross, C. Adamo, J. Jaramillo, R. Gomperts, R. E. Stratmann, O. Yazyev, A. J. Austin, R. Cammi, C. Pomelli, J. W. Ochterski, P. Y. Ayala, K. Morokuma, G. A. Voth, P. Salvador, J. J. Dannenberg, V. G. Zakrzewski, S. Dapprich, A. D. Daniels, M. C. Strain, O. Farkas, D. K. Malick, A. D. Rabuck, K. Raghavachari, J. B. Foresman, J. V. Ortiz, Q. Cui, A. G. Baboul, S. Clifford, J. Cioslowski, B. B. Stefanov, G. Liu, A. Liashenko, P. Piskorz, I. Komaromi, R. L. Martin, D. J. Fox, T. Keith, M. A. Al-Laham, C. Y. Peng, A. Nanayakkara, M. Challacombe, P. M. W. Gill, B. Johnson, W. Chen, M. W. Wong, C. Gonzalez, and J. A. Pople, Gaussian, Inc., Pittsburgh P.A., 2003.

34. A. D. Becke, J. Chem. Phys., 98, 5648 (1993).

35. C. Lee, W. Yang, and R. G. Parr, Phys. Rev. B: Condens. Matter Mater. Phys., 37, 785 (1988)

36. B. Miehlich, A. Savin, H. Stoll, and H. Preuss, Chem. Phys. Lett., 157, 200 (1989).

37. Y. S. Lee and M. Kertesz., J. Chem. Phys., 88, 2609 (1988).

38. R. Hoffmann, C. Janiak, and C. Kollmar, Macromolecules, 24, 3725 (1991). 